\title{
Effect of Coating Method on the Survival Rate of L. plantarum for Chicken Feed
}

\author{
Sang-Yoon Lee ${ }^{1}$, Yeon-Ji Jo², Mi-Jung Choi ${ }^{1}$, Boo-Yong Lee ${ }^{3}$, Jong-Kwon Han ${ }^{4}$, \\ Jae Kag Lim ${ }^{5}$, and Jae-Wook Oh* \\ Department of Animal Biotechnology, Konkuk University, Seoul 143-701, Korea \\ ${ }^{1}$ Department of Bioresources and Food Science, Konkuk University, Seoul 143-701, Korea \\ ${ }^{2}$ Department of Bioindustrial Technologies, Konkuk University, Seoul 143-701, Korea \\ ${ }^{3}$ Department of Food Science and Biotechnology, CHA University, Sungnam 463-836, Korea \\ ${ }^{4}$ MILAE Resources ML Co., LTD., Seoul 138-050, Korea \\ ${ }^{5}$ Department of Chemical Engineering and Biotechnology, Korea Polytechnic University, Gyeonggi 429-793, Korea
}

\begin{abstract}
This study was designed to find the most suitable method and wall material for microencapsulation of the Lactobacillus plantarum to maintain cell viability in different environmental conditions. To improve the stability of $L$. plantarum, we developed an encapsulation system of L. plantarum, using water-in-oil emulsion system. For the encapsulation of L. plantarum, corn starch and glyceryl monostearate were selected to form gel beads. Then $10 \%(\mathrm{w} / \mathrm{v})$ of starch was gelatinized by autoclaving to transit gel state, and cooled down at $60^{\circ} \mathrm{C}$ and mixed with L. plantarum to encapsulate it. The encapsulated L. plantarum was tested for the tolerance of acidic conditions at different temperatures to investigate the encapsulation ability. The study indicated that the survival rate of the microencapsulated cells in starch matrix was significantly higher than that of free cells in low $\mathrm{pH}$ conditions with relatively higher temperature. The results showed that corn starch as a wall material and glycerol monostearate as a gelling agent in encapsulation could play a role in the viability of lactic acid bacteria in extreme conditions. Using the current study, it would be possible to formulate a new water-in-oil system as applied in the protection of $L$. plantarum from the gastric conditions for the encapsulation system used in chicken feed industry.
\end{abstract}

Keywords Lactobacillus plantarum, encapsulation stability, water in oil emulsion, gel bead

\section{Introduction}

Antibiotics are the biological medicine originated from microorganisms, which prevent bacterial growth. These are important to cure infection diseases and increase weight gain and feeding efficiency for animals. However, the problems of supplying antibiotics for domestic animal are emergence of new bacteria which have resistance to antibiotics and accumulation to human that eat the meat of animals ingested it.

Lactobacillus plantarum (L. plantarum) was isolated from human saliva and can be easily found in fermented food such as Kimchi, sauerkraut, cheese and stock fish. $L$. plantarum is heat-stable and active in the $\mathrm{pH}$ range of 4.0-

\footnotetext{
*Corresponding author: Jae-Wook Oh, Department of Animal Biotechnology, Konkuk University, Seoul 143-701, Korea. Tel: 82-2-2049-6271, Fax: 82-2-455-1044, E-mail: ohjw@konkuk. ac.kr
}

6.5. It can resist the effects of bile acids in the upper small intestine when ingested, and colonizes and grows in large intestine. Being used as a probiotic, its biotherapeutic applications have been increasingly recognized (De Simone et al., 1991; Lee and Salminen, 1995). It was proved that $L$. plantarum can enhance the intestinal integrity, metabolic activity of intestinal cells and stimulate immune responses (Rajam et al., 2012). Also, L. plantarum is a lactic acid bacteria (LAB) with probiotic capacity. LABs are among the most important probiotic microorganisms typically associated with the human gastrointestinal tract (GIT) (Dolly et al., 2011; Gbassi et al., 2009).

Recently, pro- or prebiotics are increasingly paid attention to substitute antibiotics as an animal feeding. Probiotics are defined as a live microbial feed supplement which beneficially affects the host animal by improving its microbial balance (Fuller, 1993; Havenaar and Huis in't Veld, 1992). Probiotics provide many health benefits including immune stimulation, cholesterol reduction, in- 
hibition of pathogen growth, maintenance of a healthy gut microflora, prevention of cancer, improvement in lactose utilization, prevention of diarrhoeal diseases or constipation, absorption of calcium, and synthesis of vitamins and predigestion of proteins (De Simone et al., 1991; Fuller, 1993; Havenaar and Huis in’t Veld, 1992; Jankowski et al., 1997; Lee and Salminen, 1995). In addition, it have been supplemented to diverse food products to create "functional foods or nutraceuticals" in global markets (Stanton et al., 2001). To provide functional properties, the minimum level of viable bacteria is approximately $10^{6}$ $\mathrm{CFU} / \mathrm{mL}$ of product at the expiry date, and the suggested therapeutic dose is $10^{8}-10^{9}$ viable cells per day. Furthermore, they contribute to the general well-being of the host, beyond inherent general nutrition due to the important symbiosis they establish with the host without any side effects caused by antibiotics (Kurmann and Robinson, 1991).

However, probiotics may not survive in sufficient number and retain their activity prior to consumptions, due to processing procedures such as oxygen stress, freezing, drying, and fermentation. Especially, it may be affect during their passage through gastro-intestinal tract (GIT) (Gismondo et al., 1999; Pimentel-González et al., 2009).

Therefore, encapsulation has been as a potential mechanism to enhance the viability of probiotics in the in the stomach acids or through GIT (Anal et al., 2003; Anal and Stevens, 2005). Encapsulation is defined as a technology of packaging solids, liquids or gaseous materials in miniature, sealed capsules that can release their contents at controlled rates under the influences of specific conditions (Anal and Stevens, 2005; Anal and Singh, 2007). In general, encapsulation method can be used for many applications in the food and pharmaceutical industries including solubilizing water insoluble materials, masking flavours, colours or odours, extending the shelf life and protecting component. As well, encapsulation techniques have been widely applied to enhance viability of probiotic bacteria in commercial products and it can protect the active probiotics with proper coating materials such as proteins and polysaccharides (Heidebach et al., 2009; Krasaekoopt et al., 2004; Rajam et al., 2012) controlling release of probiotics in and out of microcapsules. Especially, they used for protecting probiotics from extra environments such as $\mathrm{pH}$, temperature, medium composition and other factors (Shima et al., 2006). For using microencapsulation technique, many coating materials have been studied in conjunction with alginate beads to enhance the protection of Lactobacillus and Bifidobacterium cells in acidic environments; these include chitosan, poly-l-lysine and whey proteins, with the former being the most well studied coating polymer (Chavarri et al., 2010; Gbassi et al., 2009; Krasaekoopt et al., 2004; Nualkaekul et al., 2012). Among the microencapsulation techniques for protecting probiotics, water in oil (W/O) emulsion system including L. plantarum may serve as suitable wall materials to encapsulate and protect probiotic bacteria in GIT. In addition, it may be used as a potential biocapsule to encapsulate bacterial for commercial utilization in food products or feed additives.

The aim of this work was to determine the suitability of coating agents including wall material (corn starch) and gelling agents (glyceryl monostearate or glyceryl monoolein) for formation of W/O emulsion system, and to improve the survival of the encapsulated L. plantarum in $\mathrm{W} /$ $\mathrm{O}$ emulsions under different temperature $\left(37^{\circ} \mathrm{C}\right.$ and $\left.40^{\circ} \mathrm{C}\right)$ and $\mathrm{pH}$ (pH 2 and 7).

\section{Materials and Methods}

\section{Materials}

Corn starch used as wall material was purchased from Daejung Chemical \& Metals (Korea). Glyceryl monostearate and glyceryl monoolein were obtained from Daejung Chemical \& Metals (Korea) and TCI (Tokyo Chemical Industry Co., Japan), respectively. For preparation of water in oil emulsion system, soybean oil was purchased from Hae-phyo (Korea).

\section{Microorganism}

The bacterial strain used in this study was Lactobacillus platarum 10hk 2 culture, provided from Milae Resources ML Research Institute (Korea). The strain was cultured on Lactobacilli MRS broth (Difco ${ }^{\mathrm{TM}}$, USA) at $37 \pm$ $1^{\circ} \mathrm{C}$ for $24 \mathrm{~h}$ and working stocks of cultures were maintained in $20 \%$ glycerol suspension frozen at $-18^{\circ} \mathrm{C}$.

\section{Concentrated cell culture preparation}

Active culture for experiments were prepared by transferring one loof of cells from stock cultures to flask of MRS broth, which were incubated at growth temperature of $37 \pm 1^{\circ} \mathrm{C}$ for $24 \mathrm{~h}$ in a shacking incubator at $90 \mathrm{rpm}$. The cells were collected by centrifugation (Centrifugal separator, 1736R, LaboGene, Korea) at 4,000 rpm for $10 \mathrm{~min}$ at $4^{\circ} \mathrm{C}$. After removal of supernatant, cell pellets were washed with sterile $0.9 \%(\mathrm{w} / \mathrm{v})$ saline solution. There average cell concentrations of these cells were approximately $8 \mathrm{Log}$ CFU/mL. 


\section{Encapsulation of $L$. plantarum through coating ma- terials}

We prepared three types of corn starch solutions (only starch solution; starch solution with monoolein; starch solution with monostearate) to confirm effect of coating materials. Corn starch solutions of 3\% (w/v) with glyceryl monoglyceride of $0.1 \%(\mathrm{w} / \mathrm{v})$ were mixed using stirrer for $1 \mathrm{~h}$ and autoclaved (JEIOTEC, Korea) and cooled at $30^{\circ} \mathrm{C}$. After, the samples inoculated $5 \%(\mathrm{v} / \mathrm{v})$ L. plantarum suspension with ratio of 100:1 (v:v) and were pour plated on MRS agar (Difco ${ }^{\mathrm{TM}}$, USA) plates after appropriate 10 -fold serial dilution in $0.9 \%(\mathrm{w} / \mathrm{v})$ saline solutions. Colony forming units (CFU) were enumerated manually after incubation at $37 \pm 1^{\circ} \mathrm{C}$ for $24 \mathrm{~h}$.

\section{Microencapsulation of $L$. plantarum through hydro- gel in oil system}

L. plantarum was microencapsulated by mixing culture concentrated with corn starch as wall material and glyceryl monostearate as gelling agent. First, 10\% (w/v) Corn starch and $0.1 \%(\mathrm{w} / \mathrm{v})$ glyceryl monostearate were mixed with distilled water and stirred until complete dissolution. After, the mixture was autoclaved and cooled to $60^{\circ} \mathrm{C}$. The freshly harvested cell concentration of $10 \%(\mathrm{v} / \mathrm{v})$ was mixed with solution of corn starch and glyceryl monostearate. The water-in-oil (W/O) emulsions were prepared by emulsifying a continuous phase (W) made up by corn starch solutions containing $8 \mathrm{Log} \mathrm{CFU} / \mathrm{mL}$ into an dispersed phase $(\mathrm{O})$ made up by corn oil, and the ratio of dispersed phase to continuous phase was set at 2:1 (w:w). Emulsification was carried out with the high speed homogenizer (ULTRA-TURRAX ${ }^{\circledR}$ T25, IKA ${ }^{\circledR}$ Labotechnik, Germany) at $11,000 \mathrm{rpm}$ for $5 \mathrm{~min}$. To collect of pure hydrogel microcapsules, the $\mathrm{W} / \mathrm{O}$ emulsions were centrifuged at $800 \mathrm{rpm}$ for $10 \mathrm{~min}$ at $4^{\circ} \mathrm{C}$, and then the samples were washed with $0.9 \%(\mathrm{w} / \mathrm{v})$ saline solutions to eliminate soybean oil residue. Pure hydrogel microcapsules of five gram were diluted with $20 \mathrm{~mL}$ of $0.9 \%(\mathrm{w} / \mathrm{v})$ saline solutions, and the samples were stored at $4^{\circ} \mathrm{C}$ prior to use.

\section{Analysis of thermal properties}

Differential scanning calorimetry (DSC) studies were used by a DSC 200F3 apparatus (Netzsch-Geraetebau Gmbh, Germany) to confirm the optimal gelling agent. Monoglycerides of two types such as monoolein and monostearate were determined by DSC. Temperature calibration was performed using indium. The samples were weight at an accuracy of $3 \pm 0.01 \mathrm{mg}$ and were hermetically sealed in an aluminum pan. Each sample was scanned from $20^{\circ} \mathrm{C}$ to $200^{\circ} \mathrm{C}$ with a heating rate of $20^{\circ} \mathrm{C} /$ min under nitrogen gas injection. Through the DSC analysis, we confirmed melting point of each monoglyceride.

\section{Microscopic observation}

Wall materials and entrapped L. plantarum into the W/O emulsions were observed with optical microscope (Olympus CX31RTSF, Japan).

\section{Survival of free and encapsulated $L$. plantarum}

To determine the viable counts the entrapped L. plantarum, hydrogel microcapsules and non-entrapped control cells culture were stored at $37^{\circ} \mathrm{C}$ for $0,24,48 \mathrm{~h}$. Cell counts were calculated from the colonies on lactobacilli MRS agar plates after $48 \mathrm{~h}$ incubation at $37^{\circ} \mathrm{C}$ under anaerobic conditions, and thus expressed as colony-forming units per $\mathrm{mL}(\mathrm{CFU} / \mathrm{mL})$.

For confirming of $\mathrm{pH}$ of L. plantarum, $1 \mathrm{~mL}$ of hydrogel microcapsules and $1 \mathrm{~mL}$ of non-entrapped control cells culture were inoculated by separate into $9 \mathrm{~mL} \mathrm{pH} 2$ and pH 7 solutions. Samples were incubated at $37^{\circ} \mathrm{C}$ and $40^{\circ} \mathrm{C}$ and taken at different time intervals to determine the complete release of encapsulated $L$. plantarum by plating as described previously.

\section{Viscosity measurement}

Initially, one gram of hydrogel microcapsules was poured into the CP50-2 plate of a Rheometer ${ }^{\circledR}$ (Anton Paar, Austria). Hydrogel microcapsules were stored at $37^{\circ} \mathrm{C}$ and $40^{\circ} \mathrm{C}$. After 0,1 , and $2 \mathrm{~h}$, the microcapsules were sampled and analyzed using with $\mathrm{CP} 50-2$ probe with shear rate of $50 / \mathrm{s}$ for $20 \mathrm{~min}$.

\section{Statistical analysis}

The data were analyzed by using one-way analysis of variance with storage periods. An analysis of variance was performed on all the variables using the General Linear Model (GLM) procedure (SAS 9.3, SAS Institute, USA). Differences among the means were compared using Tukey's Studentized Range (HSD) Test $(p<0.05)$.

\section{Results and Discussion}

\section{Morphological properties of bulky mixture between \\ L. plantarum and starch}

To encapsulate the $L$. plantarum for the chicken feeds within gelatinized starch, the morphological comparison of each used samples was needed to distinguish the structural properties. In the present study, corn starch was 


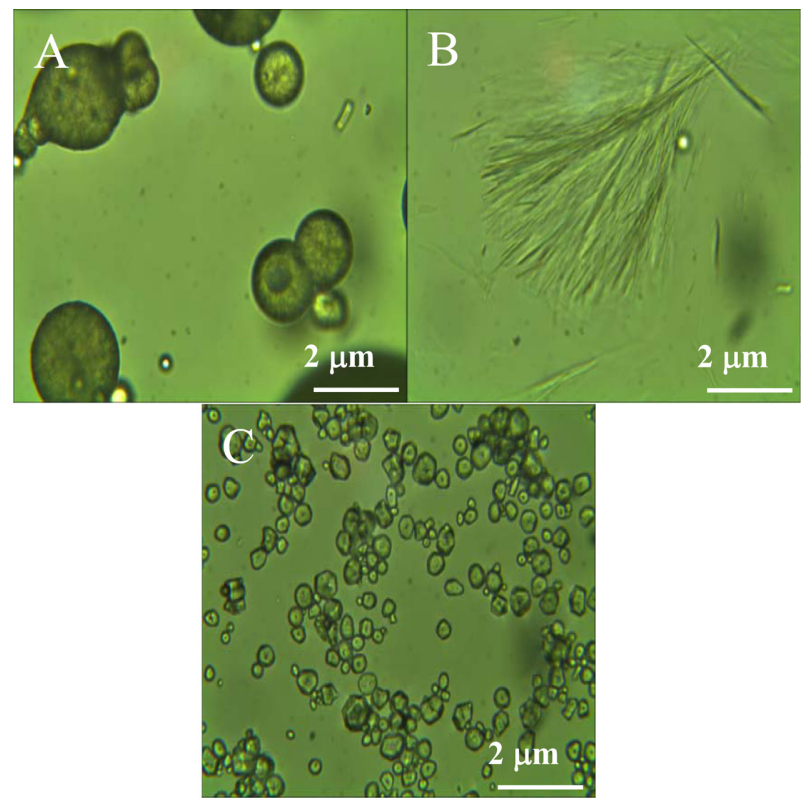

Fig. 1. Structures of (A) corn starch, (B) glyceryl monoolein and $(\mathrm{C})$ glyceryl monostearate as a raw material.

selected as a wall material for the encapsulation of $L$. plantarum due to its hydrophilic properties. For the formation of gel form, glyceryl monostearate or glyceryl monoolein was mixed into the gelatinized corn starch as a gelling agent. Sultana et al. (2000) postulated that the addition of starch to an alginate mixture increased recovery of encapsulated cells without altering its sensitive to acid. Fig. 1 shows the optical microscope observation of non-gelatinized corn starch, glyceryl monoolein, and glyceryl monostearate. The granule of non-gelatinized corn starch and glyceryl monostearate can be clearly seen in the suspension with distilled water (Fig. 1A and C). On the other hand, the glyceryl monoolein were not visible clearly, but the fibrous form can be observed (Fig. 1B).

In order to develop the formulation of encapsulation for L. plantarum, the gelatinized corn starch was mixed with or without glyceryl monoolein or glyceryl monostearate. Their structure was observed by optical microcopy and shown in Fig. 2. Comparing to control (without gelling agent), the structures of matrix prepared with gelling agent showed relatively small and uniform particles regardless of type of gelling agent. However, all images showed the irregular form, namely, the rounded shape or coating membrane could not be seen at the simple mixing treatment $L$. plantarum and starch irrespective gelling agent. From these observations, the coating membrane was not clearly shown in the bulky mixture between gelatinized starch and L. plantarum. A similar result was reported by Sultana et al. (2000). They demonstrated the positive role

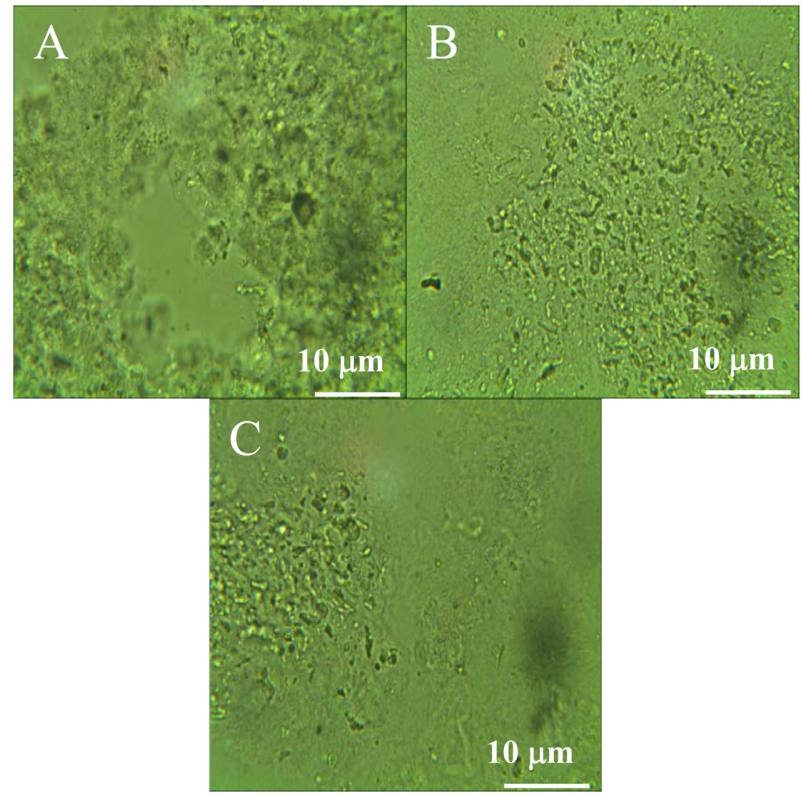

Fig. 2. Optical microscopic observation of $L$. plantarum mixed into gelatinized starch matrix (A) without gelling agent (glyceryl monostearate or glyceryl monoolein), (B) with glyceryl monostearate and $(C)$ with glyceryl monoolein as a gelling agent.

of incorporation of resistant starch and glycerol into the alginate mix during encapsulation. Therefore, we have attempted to manufacture the round shape of capsule in order to produce the obvious membrane of gelatinized starch on the surface L. plantarum. W/O emulsion formation was applied into this system and it will be described in followed section.

\section{DSC}

The thermal properties of glyceryl monoolein and glyceryl monostearate were presented in Fig. 3. The melting point of glyceryl monoolein and glyceryl monostearate was presented at $42.1^{\circ} \mathrm{C}$ and $187.5^{\circ} \mathrm{C}$. When glyceryl monostearate selected as a immolibizer (gelling agent), we expected that bulky mixture of the coated L. plantarum can maintain the solid form at the room temperature. Glyceryl monoolein initiate to melt from $30^{\circ} \mathrm{C}$, whereas glyceryl monostearate still remained solid state at the same temperature. From these results, it was expected that glyceryl monostearate was proper as a gelling agent for the protection of $L$. plantarum at chicken body temperature of around $40-41^{\circ} \mathrm{C}$. Therefore, glyceryl monostearate was selected not only as a gelling agent but also as an emulsifier for the stabilizer in the W/O emulsion system. Relevant studies have shown that melting point of glyceryl monoolein and glyceryl monostearate for the pure form 

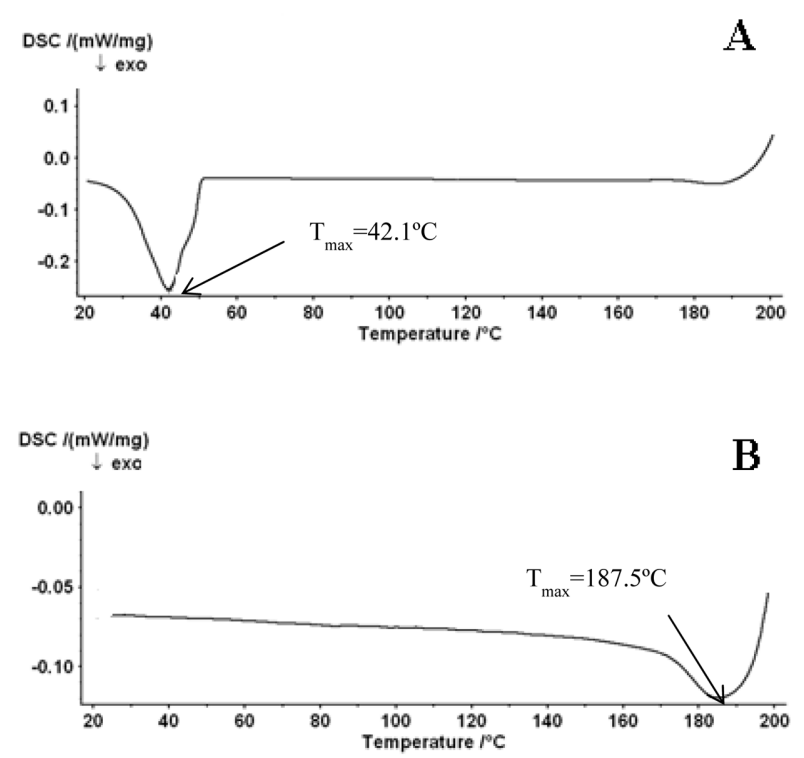

Fig. 3. Thermal properties of (A) glyceryl monoolein and (B) glyceryl monostearate, melting point of glyceryl monoolein and glyceryl monostearate were 42.1 and $187.5^{\circ} \mathrm{C}$.

was $36^{\circ} \mathrm{C}$ and $81.5^{\circ} \mathrm{C}$ respectively (Ganem-Quintanar et al., 2000; Raymond and Cornish, 1968). The melting point of glyceryl monostearate was higher than that of glyceryl monoolein. This might be the reason of the different type of fatty acid of the monoglyceride.

\section{Morphological properties of encapsulation of $L$. plantarum by W/O emulsion formation}

The aqueous phase and oil phase was mixed at the ratio of 2:1 (v:v) to disperse aqueous phase droplet into the oil continuous phase with the addition of glyceryl monostearate. Their morphological structure was shown in Fig. 4. L. plantarum without starch showed the suspended dispersion in distilled water (Fig. 4A). The empty starch gel did not present any L. plantarum, whereas the starch hydrogel as a dispersed phase contained L. plantarum surrounded gelatinized starch membrane. According to Muthukumarasamy et al. (2006), the shape of microcapsules produced by various methods such as extrusion was almost round shape with stable $\mathrm{W} / \mathrm{O} / \mathrm{W}$ emulsion. They reported that lactic acid bacteria encapsulated with alginate and starch can be protected from the acidic condition (Muthukumarasamy et al., 2006).

\section{Effect of $\mathrm{pH}$ and temperature on viability of $L$. plantarum}

Viabilities of L. plantarum during storage period at acidic and neutral conditions at $37^{\circ} \mathrm{C}$ are depicted in Fig. 5. Initially, viable count of $L$. plantarum in control was esti-

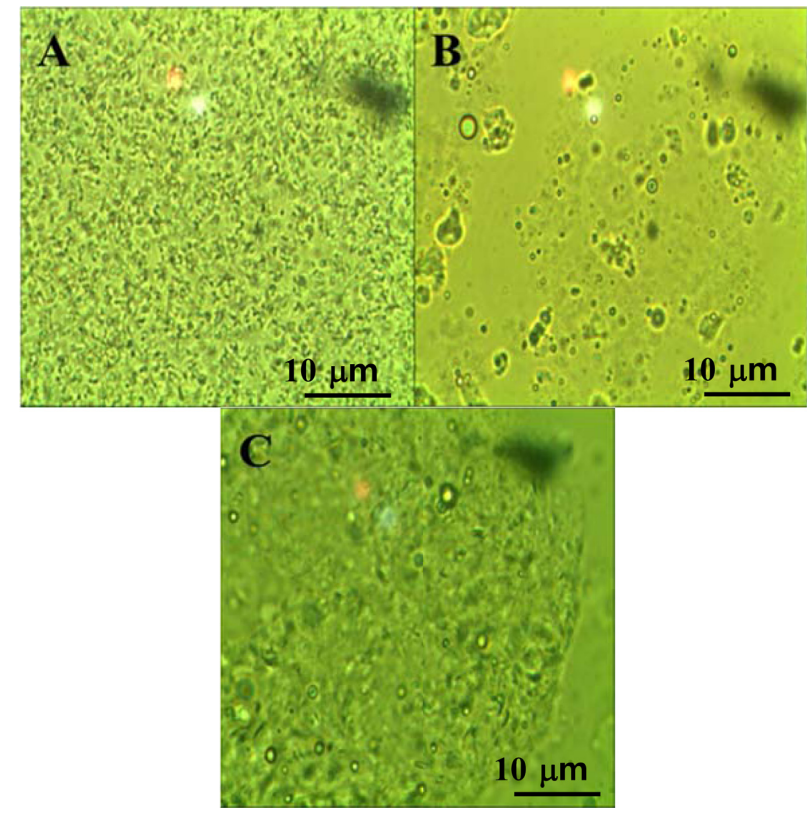

Fig. 4. Morphological structure of (A) L. plantarum suspension without starch, (B) starch bead without $L$. plantarum and (C) L. plantarum coated within starch gel by $W / O$ emulsion.

mated about 9.5 Log CFU/mL, and no general changes in the viability was shown during $6 \mathrm{~h}$ storage. In the case of capsuled sample, L. plantarum tended to decrease with increasing time, and significant decrease was obtained after $6 \mathrm{~h}$ storage $(p<0.05)$. Under the acidic condition ( $\mathrm{pH} 2)$, drastic decrease in the L. plantarum count was observed regardless of capsulation. Both treatments showed complete inactivation within $2 \mathrm{~h}$. However, capsuled sample showed more resistance $(2 \mathrm{~h})$ under extreme $\mathrm{pH}$ condition comparing to $1 \mathrm{~h}$ of untreated L. plantarum. Meanwhile, both treatments exhibited higher viability at neutral condition, where $L$. plantarum count was decreased after $1 \mathrm{~h}$ $(p<0.05)$ then the decrease in the count was gradual. In particular, capsuled L. plantarum exhibited highly stable at the neutral condition. Shima et al. (2009) reported that the survival rate of $L$. acidophilus incorporated in the inner-water phase of a $\mathrm{W} / \mathrm{O} / \mathrm{W}$ emulsion was highest under the model digestive juice containing the bile acids. They reported that the viability of free lactic acid bacteria dispersed in the juice was rapidly decreased, then, a colony on the MRS broth agar plate was not detected in 1.33 h. Chandramouli et al. (2000) observed that L. acidophilus encapsulated by calcium alginate can be significantly survived at gastric condition ( $\mathrm{pH} 2$ ) than free cells.

At the elaborated incubation temperature $\left(40^{\circ} \mathrm{C}\right)$, the viability of $L$. plantarum showed similar pattern to those obtained at $37^{\circ} \mathrm{C}$ (Fig. 6). For control, both treatments 

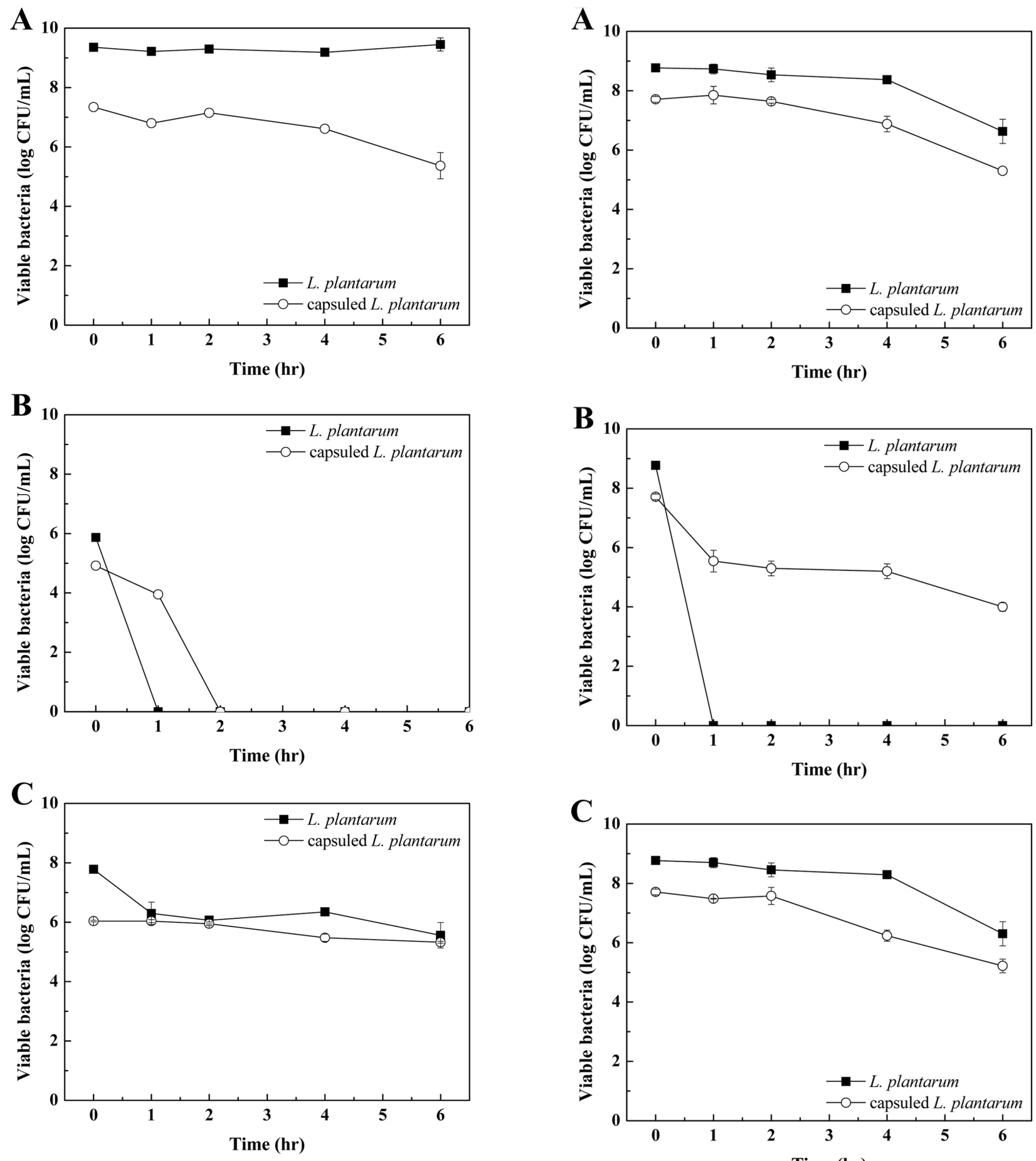

Fig. 5. Effect of $\mathrm{pH}$ on the viability of $\boldsymbol{L}$. plantarum stored at (A) control, (B) pH 2 and (C) pH 7 under $37^{\circ} \mathrm{C}$.

showed a steady decrement for $4 \mathrm{~h}$ incubation, thereafter the decrease was drastic. Although capsuled L. plantarum showed same pattern to uncapsuled sample, the count of capsuled sample was lower about 1.5 Log CUF/mL than those of uncapsuled. At acidic condition ( $\mathrm{pH} 2$ ), L plantarum was deactivated after $1 \mathrm{~h}$ incubation, while capsuled sample showed stable and minor decrease with incuba-

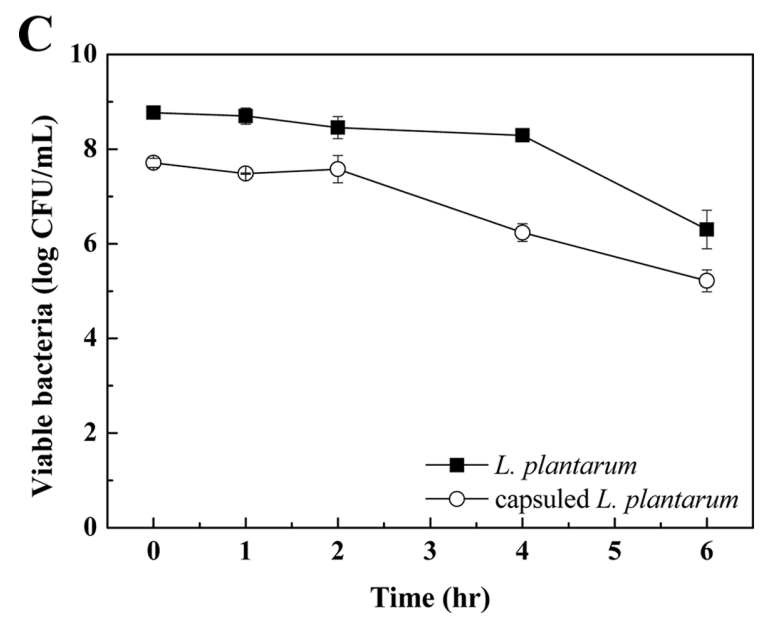

Fig. 6. Effect of $\mathrm{pH}$ on the total viable count of $\boldsymbol{L}$. plantarum stored at (A) control, (B) pH 2 and (C) pH 7 under $40^{\circ} \mathrm{C}$.

tion time. The viability of L. plantarum at neutral condition was similar to the counterpart of controls.

\section{Effect of temperature on rheological properties of} starch bead

The viscosities of starch bead collected at varying incu- 



Fig. 7. The viscosity curve of starch bead measured at (A) $37^{\circ} \mathrm{C}$ and $(\mathrm{B}) 40^{\circ} \mathrm{C}$.

bation times at $37^{\circ} \mathrm{C}$ were similar to one another and ranged 3-4 Pa.s (Fig. 7A). On the other hand, the viscosities of starch bead at $40^{\circ} \mathrm{C}$ were different depending on incubation time. Initially ( $0 \mathrm{~min})$, starch bead showed similar viscosity to those found at $37^{\circ} \mathrm{C}$. However, the viscosity of bead incubated at $40^{\circ} \mathrm{C}$ for $60 \mathrm{~min}$ had about twice higher than that incubated for $0 \mathrm{~min}$. The viscosity of starch bead incubated for 120 min tended to decrease slightly, still the viscosity was higher than that for $0 \mathrm{~min}$.

\section{Conclusions}

Encapsulated starch gel bead of L. plantarum was produced by water in oil (W/O) emulsion system with glycerol monostearate and corn starch. Encapsulated bead gel showed round shape with around $20 \mathrm{~mm}$ of diameter containing of $L$. plantarum. Lactic acid bacteria in the water phase at W/O emulsion system significantly persisted representing higher viability in the acidic condition. The results of this study can be concluded that corn starch as a wall material and glycerol monostearate as a gelling agent can play a role as a coating material for lactic acid bacteria from the extreme condition after encapsulation. Therefore, this formulation might be applied into the chicken feed industry instead of antibiotics to improve the health of chicken.

\section{Acknowledgements}

This research was supported by a grant from Korea Institute of Planning and Evaluation for Technology in Food, Agriculture, Forestry, and Fisheries (iPET Project No. 112022-3).

\section{References}

1. Anal, A. K., Bhopatkar, D., Tokura, S., Tamura, H., and Stevens, W. F. (2003) Chitosan-alginate multilayer beads for gastric passage and controlled intestinal release of protein. Drug Dev. Ind. Pharm. 29, 713-724.

2. Anal, A. K. and Singh, H. (2007) Recent advances in microencapsulation of probiotics for industrial applications and targeted delivery. Trends Food Sci Technol. 18, 240-251.

3. Anal, A. K. and Stevens, W. F. (2005) Chitosan-alginate multilayer beads for controlled release of ampicillin. Int. J. Pharm. 290, 45-54.

4. Chandramouli, V., Kailaspathy, K., Peiris, P., and Jones, M. (2004) An improved method of microencapsulation and its evaluation to protect Lactobacillus spp. in simulated gastric conditions. J. Microbiol. Methods. 56, 27-35.

5. Chavarri, M., Maranon, I., Ares, R., Ibanez, F. C., Marzo, F., and Villaran, M. C. (2010) Microencapsulation of a probiotic and prebiotic in alginate-chitosan capsules improves survival in simulated gastro-intestinal conditions. Int. J. Food Microbiol. 142, 185-189.

6. De Simone, C., Rosati, E., Moretti, S., Salvadori, B., Vesely, R., and Jirillo, E. (1991) Probiotics and stimulation of the immune response. Eur. J. Clin. Nutr. 45, 32-34.

7. Dolly, P., Anishaparvin, A., Joseph, G. S., and Anandharamakrishnan, C. (2011) Microencapsulation of Lactobacillus plantarum (mtcc 5422) by spray-freeze-drying method and evaluation of survival in simulated gastrointestinal conditions. $J$. Microencapsul. 28, 568-574.

8. Fuller, R. (1993) Probiotic foods: current use and future developments. Int. Food Ingred. 3, 23-26.

9. Ganem-Quintanar, A., Quintanar-Guerrero, D., and Buri, P. (2000) Monoolein: A review of the pharmaceutical applications. Drug. Dev. Ind. Pharm. 26, 809-820.

10. Gbassi, G. K., Vandamme, T., Ennahar, S., and Marchioni, E. (2009) Microencapsulation of Lactobacillus plantarum spp in an alginate matrix coated with whey proteins. Int. J. Food Microbiol. 129, 103-105.

11. Gismondo, M. R., Drago, L., and Lombardi, A. (1999) Review of probiotics available to modify gastrointestinal flora. 
Int J Antimicrob Agents. 12, 287-292.

12. Havenaar, R. and Huis in't Veld, J. H. J. (1992) Probiotics: a general view. In: The lactic acid bacteria volume 1. Wood, B. J. B (ed) Springer US, US, Vol. 1, pp. 151-170.

13. Heidebach, T., Först, P., and Kulozik, U. (2009) Transglutaminase-induced caseinate gelation for the microencapsulation of probiotic cells. Int. Dairy J. 19, 77-84.

14. Jankowski, T., Zielinska, M., and Wysakowska, A. (1997) Encapsulation of lactic acid bacteria with alginate/starch capsules. Biotechnol. Tech. 11, 31-34.

15. Krasaekoopt, W., Bhandari, B., and Deeth, H. (2004) The inuence of coating materials on some properties of alginate beads and survivability of microencapsulated probiotic bacteria. Int. Dairy J. 14, 737-743.

16. Kurmann, J. A. and Robinson, R. K. (1991) The health potential of products containing bifidobacteria. In: Therapeutic properties of fermented milks. Robinson, R. K. (ed) Elsevier Applied Science NY, pp. 117-157.

17. Lee, Y. K. and Salminen, S. (1995) The coming of age of probiotics. Trends Food Sci. Tech. 6, 241-245.

18. Muthukumarasamy, P., Allan-Wojtas, P., and Holly, R. A. (2006) Stability of Lactobacillus reuteri in different types of microcapsules. J Food Sci. 71, 20-24.

19. Nualkaekul, S., Lenton, D., Cook, M. T., Khutoryanskiy, V. V., and Charalampopoulos, D. (2012) Chitosan coated alginate beads for the survival of microencapsulated Lactobacillus plantarum in pomegranate juice. Carbohyd. Polym. 90, 1281-
1287.

20. Pimentel-González, D. J., Campos-Montiel, R. G., Lobato-Calleros, C., Pedroza-Islasd, R., and Vernon-Carter, E. J. (2009) Encapsulation of Lactobacillus rhamnosus in double emulsions formulated with sweet whey as emulsifier and survival in simulated gastrointestinal conditions. Food Res Int. 42, 292297.

21. Rajam, R., Karthik, P., Parthasarathi, S., Joseph, G. S., and Anandharamakrishnan C. (2012) Effect of whey protein - alginate wall systems on survival of microencapsulated Lactobacillus plantarum in simulated gastrointestinal conditions. $J$. Funct Foods. 4, 891-898.

22. Raymond, M. and Cornish, B. S. (1968) Studies of glyceryl monostearate. J. Soc. Cosmetic Chemists. 19, 109-117.

23. Shima, M., Morita, Y., Yamashita, M., and Adachi, S. (2006) Protection of Lactobacillus acidophilus from the low $\mathrm{pH}$ of a model gastric juice by incorporation in a $\mathrm{W} / \mathrm{O} / \mathrm{W}$ emulsion. Food Hydrocoll. 20, 1164-1169.

24. Stanton, C., Gardiner, G., Meehan, H., Collins, K., Fitzgerald, G., and Lynch, P. B. (2001) Market potential for probiotics. Am. J. Clin. Nutr. 73, 476-483.

25. Sultana, K., Godward, G., Reynolds, N., Arumugaswamy, R., Peiris, P., and Kailasapathy, K. (2000) Encapsulation of probiotic bacteria with alginate-starch and evaluation of urvival in simulated gastrointestinal conditions and in yoghurt. Int. $J$. Food Microbiol. 62, 47-55.

(Received 2014.1.3/Revised 2014.3.25/Accepted 2014.3.31) 